\title{
Delivering a socially distanced boot camp for core surgical trainees during the COVID-19 pandemic: how we did it
}

\author{
Christine Blane, ${ }^{\mathrm{a}, *}$ Louise Merker, ${ }^{\mathrm{b}}$ Jonathan Mutimer, ${ }^{\mathrm{c}}$ James Coulston ${ }^{\mathrm{a}}$ and Richard Bamford ${ }^{\mathrm{a}}$ \\ ${ }^{a}$ Musgrove Park Hospital, Parkfield Drive, Taunton, TA1 5DA, UK; ${ }^{b}$ North Bristol Trust, Southmead Rd, Bristol, BS10 5NB, UK; \\ ${ }^{c}$ Gloucestershire Royal Hospital, Great Western Rd, Gloucester, GL1 3NN, UK
}

${ }^{*}$ Corresponding author at: Musgrove Park Hospital, Parkfield Drive, Taunton, TA1 5DA, UK. Email: cblane@doctors.org.uk

Date accepted for publication: 30 September 2021

\section{Abstract}

Background: Boot camps are an important way to ensure trainees have the necessary skills and confidence as they commence a new stage of training. They are an established part of many post-graduate training programmes. The COVID-19 pandemic has led to a significant disruption in post-graduate training, making boot camps an even more important intervention. Methods: This retrospective cohort study used anonymous feedback surveys to evaluate the acceptability of a new blended, socially distanced format of boot camp to trainees starting core surgical training in August 2020. Formal ethical approval was not required for this study. Results: All 27 new trainees in HEESW Severn School of Surgery attended the boot camp; over $80 \%$ participated in all three feedback surveys (22 [81\%] completed the feedback for day 1, 23 [85\%] for day 2 and 26 [96\%] for day 3). Overall feedback was positive; compared with 2019, there was no significant difference in reported readiness to perform as a core trainee, understanding of the role or the benefit gained from meeting other trainees. When asked which boot camp format the trainees preferred, they favoured all attending in one location (4.65) over the current "hub" format (3.74), which was in turn preferable to attending virtually from home (2.39). $(P<0.05)$. Conclusion: Although trainees expressed a preference for the previous model in which their entire cohort attended the boot camp together, the blended format was acceptable to trainees and allowed us to provide a boot camp while following social distancing requirements.

Keywords: surgical training; boot camp; blended learning; technology enhanced learning; surgical simulation; COVID-19

\section{Introduction}

Boot camps have become an established part of many surgical training programmes. Their aim is to ensure trainees have the necessary knowledge, technical and non-technical skills and to boost their confidence as they embark on the next stage of training. ${ }^{1-4}$

The COVID-19 pandemic caused significant disruption to surgical training in all its forms in 2020. ${ }^{5}$ Many teaching events were cancelled, trainees have been re-deployed to other specialties and training opportunities in theatre have decreased. ${ }^{6}$ In light of these pressures, we felt the core trainees' need for a dedicated boot camp was even more important this year. To comply with English social distancing guidelines, we had to make significant changes compared with the format from previous years. We used digital technology to create a blended learning boot camp, which combined face-to-face teaching with online learning. This retrospective paper aims to explore the feedback from the trainees who attended the boot camp in 2020 and to evaluate its effectiveness.

\section{Methods}

\section{Boot camp structure}

Our boot camp consists of 3 days of lecture-based and teaching sessions in small groups, including practical surgical skills teaching. Faculty include consultant surgeons with an interest in education and senior surgical trainees. Topics covered include clinical skills, technical skills training, nontechnical skills training, and opportunities to meet key individuals such as training programme directors to discuss the requirements for successfully completing the programme. It is also an opportunity for core trainees across the region to meet as a peer group. The boot camp timetable is shown in Table 1. 
Table 1. Summarized programme of boot camp 2020

\begin{tabular}{llll}
\hline Time & Day $\mathbf{1}$ & Day $\mathbf{2}$ & Day $\mathbf{3}$ \\
\hline 08.00 & Registration and welcome & Research opportunities in Severn & Emergency skills for surgery: general surgery \\
09.00 & Meet the training programme directors & Critical appraisal & Emergency skills for surgery: orthopaedic surgery \\
10.00 & ISCP: its use and navigating WBAs & Professionalism and leadership & Emergency skills for surgery: ENT \\
11.00 & Simulation training & Complex decision making & Emergency skills for surgery: vascular \\
12.00 & Association of Surgeons in Training and & Introduction to laparoscopic box & Emergency skills for surgery: urology \\
& Royal College of Surgeons & trainer programme & Lunch and meet the faculty \\
13.00 & Lunch and meet the faculty & Lunch and meet the faculty & Anaesthetics and critical care for surgeons \\
14.00 & How to be a successful core trainee & Cognitive approach to operating & Emergency skills for surgery: plastics \\
15.00 & Proactive care of older adults & Basic surgical skills refresher & \\
& undergoing surgery & & \\
\hline
\end{tabular}

ISCP, Intercollegiate Surgical Curriculum Programme; WBA, work-based assessment.

\section{Changes to facilitate social distancing}

Instead of meeting in a central location, this year we trialled a decentralized format with trainees meeting in three "hub" sites. During the first 2 days of the boot camp, trainees were split between the three "hub" sites. A blended model of learning was used; individual lectures were delivered at one hub and broadcast to the other two sites and to those isolating at home via the online platform Zoom. The number of sessions broadcast from each site was broadly equally and faculty were present at each hub. The third day was held approximately 6 weeks later with all the trainees together in a large non-clinical venue that allowed us be together while maintaining social distancing.

The hub sites were chosen because they had capacity to accommodate the number of trainees while complying with social distancing guidelines; trainees were allocated evenly between them based on their base hospitals. Masks were provided at each site for faculty and trainees. Written instructions regarding adherence to social distancing guidelines and what to do in case of developing coronavirus symptoms were given in advance and repeated verbally each day. Trainees unable to physically attend due to self-isolation or shielding requirements attended virtually via Zoom.

\section{Evaluation process}

Trainees completed online, anonymous feedback questionnaires. All trainees consented to take part in this study and were free to withdraw their consent at any point. The questionnaires were based on surveys used to evaluate previous boot camps and were updated to reflect the 2020 model.

Trainees were asked about the extent to which they felt they benefitted from each individual session, the boot camp as a whole and the acceptability of the hub model within the context of social distancing guidelines. Feedback was collecting using a Likert scale (1, strongly disagree; 5 , strongly agree). Reverse wording statements were also included to improve internal validity.

The web-based software Survey Monkey was used to distribute the surveys, which were completed by trainees on their own smart phones, tablets or computers. The results from 2020 were compared with feedback from 2019. Wilcoxon's signed rank test and ANOVA were used to assess statistical difference between the sets of results. In the weeks following the boot camp, two reminder emails were sent.

\section{Results}

All 27 new trainees in HEESW Severn School of Surgery attended the boot camp and attended evenly across the three hub sites. On day 3, four trainees attended via Zoom; their responses were included in the dataset for analysis. Feedback was collected separately for each day; 22 (81\%) completed the feedback for day 1, 23 (85\%) for day 2 and 26 (96\%) for day 3.

Feedback was extremely positive with each session having a median feedback score of $5 / 5$ and a mean score of $4 / 5$ or greater except the session on membership of the Royal College of Surgeons and the Association of Surgeons In Training, which had a median and mean score of $3 / 5$ (Table 2).

Overall trainees perceived a benefit from attending the event in person (4.38). When asked which boot camp format the trainees preferred, they favoured all attending in one location (4.65) over the current "hub" format (3.74), which was 
Table 2. Summary of feedback on boot camp

\begin{tabular}{|c|c|c|}
\hline Statement & Score $^{\mathrm{a}}$ & $\begin{array}{l}P \text { value when state- } \\
\text { ments compared }\end{array}$ \\
\hline If possible I would want all trainees to attend the bootcamp in the same location & 4.65 & $>0.05$ \\
\hline I would rather not travel at all and would prefer to attend from home & 2.39 & \\
\hline My preference is the current "hub" model & 3.74 & \\
\hline Attending in person has been more beneficial than online only would have been & 4.38 & $<0.05$ \\
\hline $100 \%$ online would have been just as good & 2.32 & \\
\hline I feel comfortable that I have been able to follow social distancing guidelines & 4.69 & $<0.05$ \\
\hline Changes should have been made to allow closer adherence to social distancing guidelines & 1.64 & \\
\hline I know who to contact if I develop COVID-19 symptoms & 4.76 & $<0.05$ \\
\hline I don't know who to contact if I develop COVID-19 symptoms & 1.32 & \\
\hline The digital technology available was sufficient to ensure a good learning experience & 3.22 & $>0.05$ \\
\hline The digital technology available was insufficient & 2.96 & \\
\hline The use of a web-based communication tool enhanced my learning & 2.96 & $>0.05$ \\
\hline The use of a web-based communication tool detracted from my learning & 3.13 & \\
\hline
\end{tabular}

${ }^{\mathrm{a}} 1$, completely disagree; 5 , completely agree.

in turn preferable to attending virtually from home (2.39). These three options were compared using ANOVA and the results were found to be statistically significant $(P<0.05)$. Trainees reported they were able to follow social distancing guidelines during the boot camp (4.69/5) and understood how to report if they developed any COVID-19 symptoms after the event (4.76).

There was no consensus on whether using an online communication platform enhanced or detracted from learning or whether the technology we used was sufficient to ensure a good experience.

\section{Comparison with 2019 boot camp}

When compared with 2019, there was no significant difference in reported readiness to perform as a core trainee, understanding of the role or the benefit gained from meeting other trainees; all these were scored as $4 / 5$. Only one session received feedback that significantly differed from the previous year; its topic was the Annual Review of Competency Process (ARCP) and use of Intercollegiate Surgical Curriculum Programme portfolio (ISCP) (Table 3).

\section{Discussion}

The start of a new training programme can be stressful for trainees. ${ }^{2}$ This transition was likely to be even more challenging during a global pandemic. We made the decision to provide a modified face-to-face boot camp because new trainees would derive significant benefits from face-to-face
Table 3. Comparison of results between 2019 and 2020

\begin{tabular}{llll}
\hline Area of feedback elicited & $\begin{array}{l}\text { Score } \\
\mathbf{2 0 1 9}^{\mathbf{a}}\end{array}$ & $\begin{array}{l}\text { Score } \\
\mathbf{2 0 2 0}^{\mathbf{a}}\end{array}$ & $\boldsymbol{P}$ value \\
\hline $\begin{array}{l}\text { Understanding of the } \\
\text { ISCP/ARCP process }\end{array}$ & 4.28 & 3.96 & $<0.05$ \\
$\begin{array}{l}\text { Useful to meet other trainees } \\
\text { Better understanding of role }\end{array}$ & 4.81 & 4.81 & $>0.05$ \\
Readiness to be a core trainee & 4.73 & 4.5 & $>0.05$ \\
\hline
\end{tabular}

ARCP, Annual Review of Competence Progression; ISCP, Intercollegiate Surgical Curriculum Programme.

${ }^{\mathrm{a}} 1$, completely disagree; 5 , completely agree.

interaction that could not be obtained otherwise. There were also practical elements of the course, such as the basic surgical skills sessions, which could not be delivered online.

Blended learning uses online resources to enhance traditional learning formats and has been widely adopted across higher education and has potential to enhance the flexibility and efficiency of learning. ${ }^{8}$ By blending traditional face-to face teaching with online learning, we were able to deliver a socially distanced boot camp.

Overall learner feedback was positive; trainees valued the opportunity to learn alongside their peers. Other studies have highlighted the importance of interactivity in blended learning. ${ }^{10,11}$ Reassuringly, this socially distanced "hub" format was acceptable to trainees and preferable to attending a completely virtual boot camp. 
When asked specifically about their readiness to perform at this level as a result of the boot camp, the trainees reported levels of confidence similar to trainees from the 2019 boot camp. Based on these findings, we feel that this year's boot camp was as effective as the previous year in preparing the trainees to begin their core training. This experience will be useful as we consider organizing others educational events where learners may not be able to gather in one place, whether this is due to social distancing requirements or other reasons.

From the perspective of the organizer, this "hub" model was significantly more complex to organize, requiring more resources including faculty and digital technology. In addition, there were some areas of the boot camp that were less effective. Feedback was mixed about the use of the online communication tool and other digital equipment. Part of the reason for these findings may have been unfamiliarity with the technology on the part of the faculty. Technical difficulties have been identified by many leaners as a significant barrier to online learning. ${ }^{9,10}$ As blended format takes a larger role in education, we may need to invest in more resources and ensure faculty are more familiar with their use.

\section{Study limitations}

Although the use of an online questionnaire allowed for rapid data collection, this method of obtaining feedback has inherent limitations. The questionnaire included quantitative data only to allow accurate comparison of data from sequential boot camps. It would be interesting to conduct qualitative research to explore trainee perceptions in more detail.

\section{Conclusion}

Our study has demonstrated that the amendments made to a core surgical training boot camp enabled us to deliver an educational event that was not inferior to those from previous years despite the challenges posed by the COVID-19 pandemic. Although vaccination programmes are underway in many countries, it appears likely that future training events will need to consider social distancing for the foreseeable future. These findings are encouraging to educators and support the development of a blended learning approach to surgical training.

\section{Conflict of interest}

The authors have no disclosures or conflicts of interest to declare.

\section{Funding}

The core surgical training boot camp was funded by Health Education England.

\section{Acknowledgement}

The authors would like to acknowledge the following collaborators: Joanne Bennet, Gloucestershire Royal Hospital; Manuk Wijeyaratne, Gloucester Royal Hospital.

\section{References}

1. Walker KG, Blackhall VI, Hogg ME, Watson AJM. Eight years of Scottish surgical boot camps: how we do it now. J Surg Educ 2020; 77(2): 235-241. https://doi.org/10.1016/j.jsurg. 2019.11.001.

2. Nakazato T, Callahan Z, Kuchta K, Linn JG, Joehl RJ, Ujiki MB. A 1-day simulation-based boot camp for incoming general surgery residents improves confidence and technical skills. Surgery 2019; 166(4): 572-579. https://doi.org/10.1016/j.surg. 2019.05.051.

3. Bamford R, Langdon L, Rodd CA, Eastaugh-Waring S, Coulston JE. Core trainee boot camp, a method for improving technical and non-technical skills of novice surgical trainees. A before and after study. Int J Surg 2018; 57: 60-65. https://doi.org/10.1016/j.ijsu.2018.03.083.

4. Kassam AF, Singer KE, Winer LK, Browne D, Sussman JJ, Goodman $\mathrm{MD}$, et al. Acquisition and retention of surgical skills taught during intern surgical boot camp. Am J Surg 2021; 221(5): 987-992. https://doi.org/10.1016/j.amjsurg.2020. 09.018 .

5. Khan KS, Keay R, McLellan M, Mahmud S. Impact of the COVID-19 pandemic on core surgical training. Scott Med J 2020; 65(4): 133-137. https://doi.org/10.1177/003693302 0949217.

6. Ellis R, Scrimgeour DSG, Brennan PA. Surgical training during the COVID-19 pandemic: preparing for future uncertainty. Br J Oral Maxillofac Surg 2020. https://doi.org/10. 1016/j.bjoms.2020.11.017.

7. Parent RJ, Plerhoples TA, Long EE, Zimmer DM, Teshome M, Mohr CJ, et al. Early, intermediate, and late effects of a surgical skills "boot camp" on an objective structured assessment of technical skills: a randomized controlled study. J Am Coll Surg 2010; 210(6): 984-989. https://doi.org/10.1016/j.jamcollsurg.2010.03.006.

8. Dziuban C, Graham CR, Moskal PD, Norberg A, Sicilia N. Blended learning: the new normal and emerging technologies. Int J Educ Technol High Educ 2018; 15: 3. https://doi.org/10. 1186/s41239-017-0087-5.

9. Ehrlich H, McKenney M, Elkbuli A. We asked the experts: virtual learning in surgical education during the COVID-19 
pandemic: shaping the future of surgical education and training. World J Surg 2020; 44(7): 2053-2055. https://doi.org/10. 1007/s00268-020-05574-3.

10. Figueroa F, Figueroa D, Calvo-Mena R, Narvaez F, Medina N, Prieto J. Orthopedic surgery residents' perception of online education in their programs during the COVID-19 pandemic: should it be maintained after the crisis? Acta
Orthop 2020; 91(5): 543-546. https://doi.org/10.1080/ 17453674.2020.1776461.

11. MacDonald DRW, Nelly DW, McMillan TE, Scottish Orthopaedic Research collaborative (SCORE). Virtual orthopaedic teaching during COVID-19: zooming around Scotland. Bull R Coll Surg Engl 2021; 103(1): 44-49. https://doi.org/10. 1308/rcsbull.2021.12. 